\title{
Healthcare Provider Competencies: A Systematic Literature Review
}

\section{Mohd Firdaus Abdullah, Abu Yazid Abu Bakar, Asiah Mohd Pilus, Mohd Radzani Abdul Razak \& Mohamad Nizam Nazaruddin}

To Link this Article: http://dx.doi.org/10.6007/IJARBSS/v11-i2/8883

DOI:10.6007/IJARBSS/v11-i2/8883

Received: 25 December 2020, Revised: 19 January 2021, Accepted: 31 January 2021

Published Online: 21 February 2021

In-Text Citation: (Abdullah et al., 2021)

To Cite this Article: Abdullah, M. F., Bakar, A. Y. A., Pilus, A. M., Razak, M. R. A., \& Nazaruddin, M. N. (2021). Healthcare Provider Competencies: A Systematic Literature Review. International Journal of Academic Research in Business and Social Sciences, 11(2), 741-756.

\section{Copyright: (c) 2021 The Author(s)}

Published by Human Resource Management Academic Research Society (www.hrmars.com)

This article is published under the Creative Commons Attribution (CC BY 4.0) license. Anyone may reproduce, distribute, translate and create derivative works of this article (for both commercial and non-commercial purposes), subject to full attribution to the original publication and authors. The full terms of this license may be seen

at: http://creativecommons.org/licences/by/4.0/legalcode

Vol. 11, No. 2, 2021, Pg. 741 - 756

Full Terms \& Conditions of access and use can be found at http://hrmars.com/index.php/pages/detail/publication-ethics 


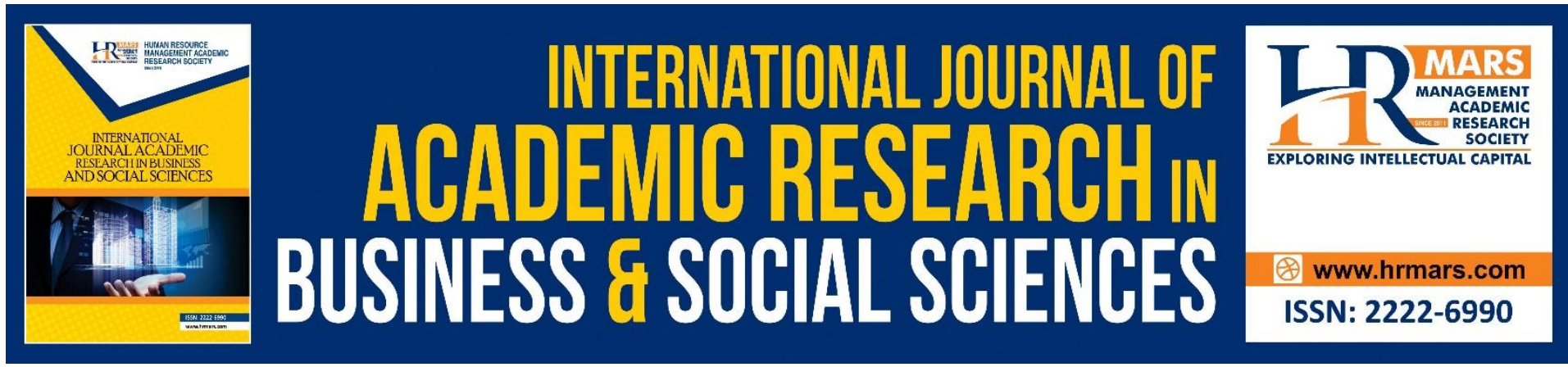

\title{
Healthcare Provider Competencies: A Systematic Literature Review
}

\author{
Mohd Firdaus Abdullah ${ }^{1 \& 2}$, Abu Yazid Abu Bakar ${ }^{1}$, Asiah Mohd \\ Pilus², Mohd Radzani Abdul Razak¹ \& Mohamad Nizam \\ Nazaruddin ${ }^{3}$ \\ ${ }^{1}$ Faculty of Education, Universiti Kebangsaan Malaysia, 43600 Bangi, Selangor, Malaysia, \\ ${ }^{2}$ Institute of Technology Management and Entrepreneurship, Universiti Teknikal Malaysia \\ Melaka, 76100 Melaka, Malaysia, ${ }^{3}$ Faculty of Psychology and Education, Universiti Malaysia \\ Sabah, 88400 Kota Kinabalu, Sabah, Malaysia \\ Email: yazid3338@ukm.edu.my
}

\begin{abstract}
The research outlines the facts surrounding the properties of healthcare executives and administrators in competencies and can be tested by the evaluation of skills, abilities, knowledge and attitudes. A comprehensive literature review from 2000 to 2020 has been undertaken to describe management and leadership characteristics that are meant to validate and/or classify the qualifications of healthcare managers. Reviews are performed for the electronic database using the set object collection criteria. A total number of 23 papers were inductively reviewed and found a capabilities model for healthcare management can be developed by drawing the competences and behaviour objects. The following classes were divided: communication, transition, professionalism, evidence, health care, operational and general. The study and evaluation of skills described in earlier studies resulted in a recommendation to extend the leadership and management skills structure for healthcare providers. It provides advice for health care staff in various forms in the development of preparatory and development directions.
\end{abstract}

Keywords: Healthcare, Literature Review, Manager Competencies

\section{Introduction}

Because of many existing and future challenges, expectations and content of health care authorities and leadership skills shift rapidly. Employee goals for the younger generation vary from older generations' aspirations. The potential workforce needs a new strategy in management (Barr \& Dowding, 2019). This study aims to recognise management and leadership skills from a holistic perspective. Clinicians and service professionals provided wellness and administration. Paper reflects on a competence point of view between managers and supervisors.

Leadership and management qualities include knowledge, abilities, skills, and personalities that are appropriate for management levels and roles in health care settings. Scientists are yet to reach a consensus on the definition of competence. For an individual to be deemed 
qualified the master must typically show his/her skills; however, academics did not agree on this principle (Lockeman, Dow \& Randell, 2019). Expertise and skills are openly and unquestionably described as inherent elements and competencies and other attributes are deduced. The elements of the skills used by a technical person are defined in two distinct meanings. The interaction between the worker and the skills practiced is based on one definition of competence, but this varies from the other (Rodriguez, Corona \& Espinosa 2019).

An existing problem is the need for leadership and management expertise in health and management as a career choice. Attempts to strengthen healthcare administrators and leaders were described as inadequate and contradictory. Efficient clinical leadership can provide health care personnel with resources and functionality for their working conditions but has no clear definition as a concept. Today, lean, competence-based management is demonstrated (Bowers, 2019). Healthcare leadership and leadership are usually professionally based, with different training and management models for doctors and nurses. Operational rituals and discipline within clinical units are essential cultural factors in healthcares. Poor international leadership and management skills are revealed by research around the world (Pihlainen, Kivinen \& Lammintakanen, 2019).

Interpersonal experience in difficult professions is important for management practice. Management and leadership skills must also complement medical expertise. There is no unconditional recognition of the leadership and management approach focused on expertise. Formal management and organizational skills' development programs were not as shockingly relevant as informal teaching strategies (Arakelian et al., 2020). Competency-based leadership learning programs are being established for clinicians in Canada, Europe and the United States of America (Ranjbar, Neishabouri \& Gorji, 2019). The literature on the management and leadership qualities of healthcare is remarkably minimal. Thus, the objective of this paper is to:

- discuss management and leadership expertise from a systematic point of view in the context of contemporary organizational theory.

\section{Methodology}

This is a literature review exercise that employs the document analysis procedure. Data collection involved scanning and screening records from relevant electronic databases. A trained information specialist was consulted on quest terminology and practice.

Reviews or publications with titles identical to the topic of the article are included in the search limit. Research describes numerous management features and skills in health care provider environments. Many samples are required of management skills, abilities, knowledge and attitude. Editorials, reviews, and explanations of management and management skills were not included. The duplication of searches using composite search words in each electronic archive provided the same findings. The search method used the parameters for inclusion and exclusion, and the results at every moveare defined in Figure 1. 
Figure 1. Systematic literature review procedure
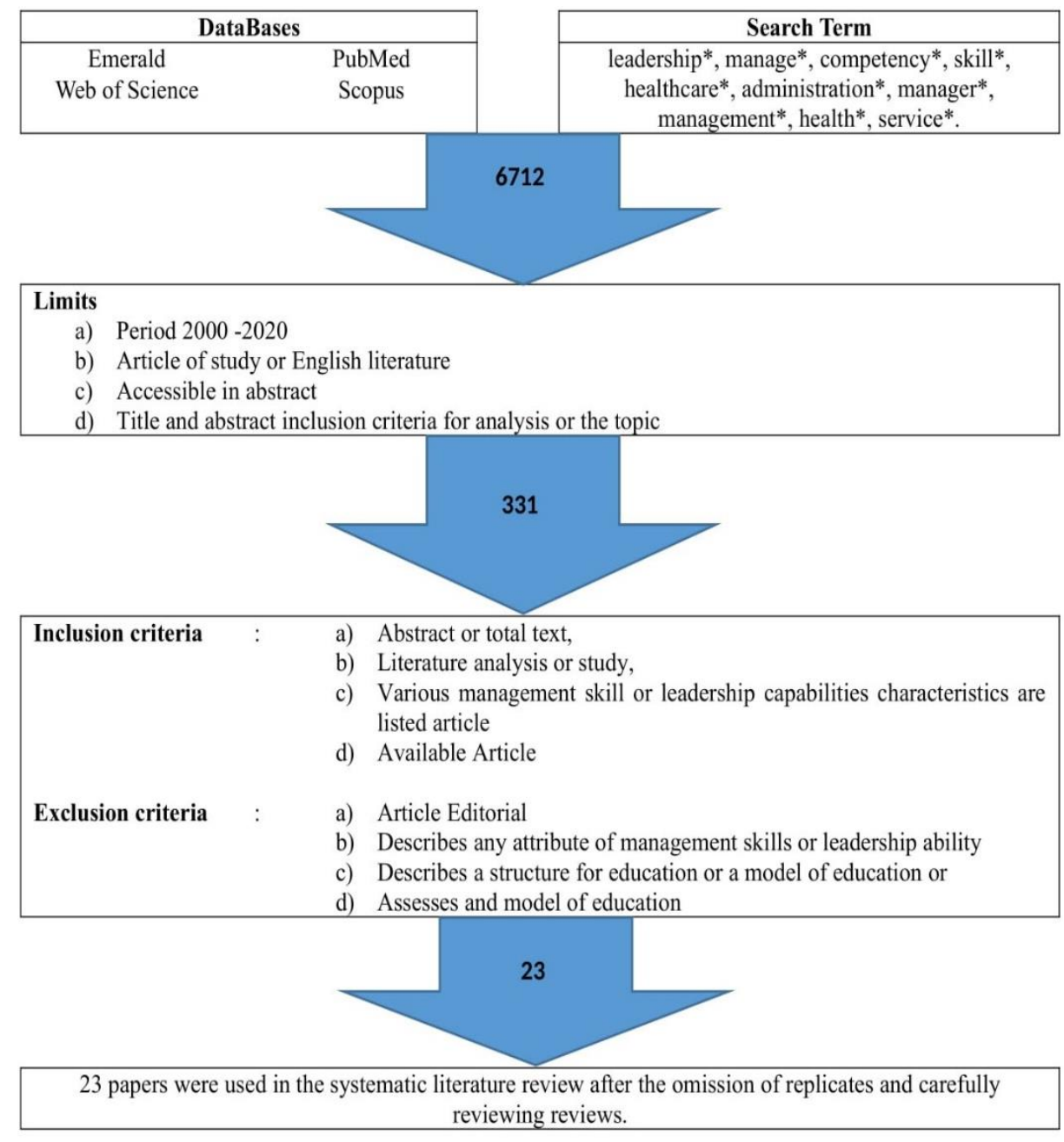

After a careful reading of the papers and the deletion of duplicates, the search results were reduced from 331 to 23 literatures. Keywords were checked by an automated document scan in the title and abstract of articles. The results were approved, with the corresponding discussion, as concentrated and precise material for this paper after the hunt. These records are chronologically presented in Table 1. 


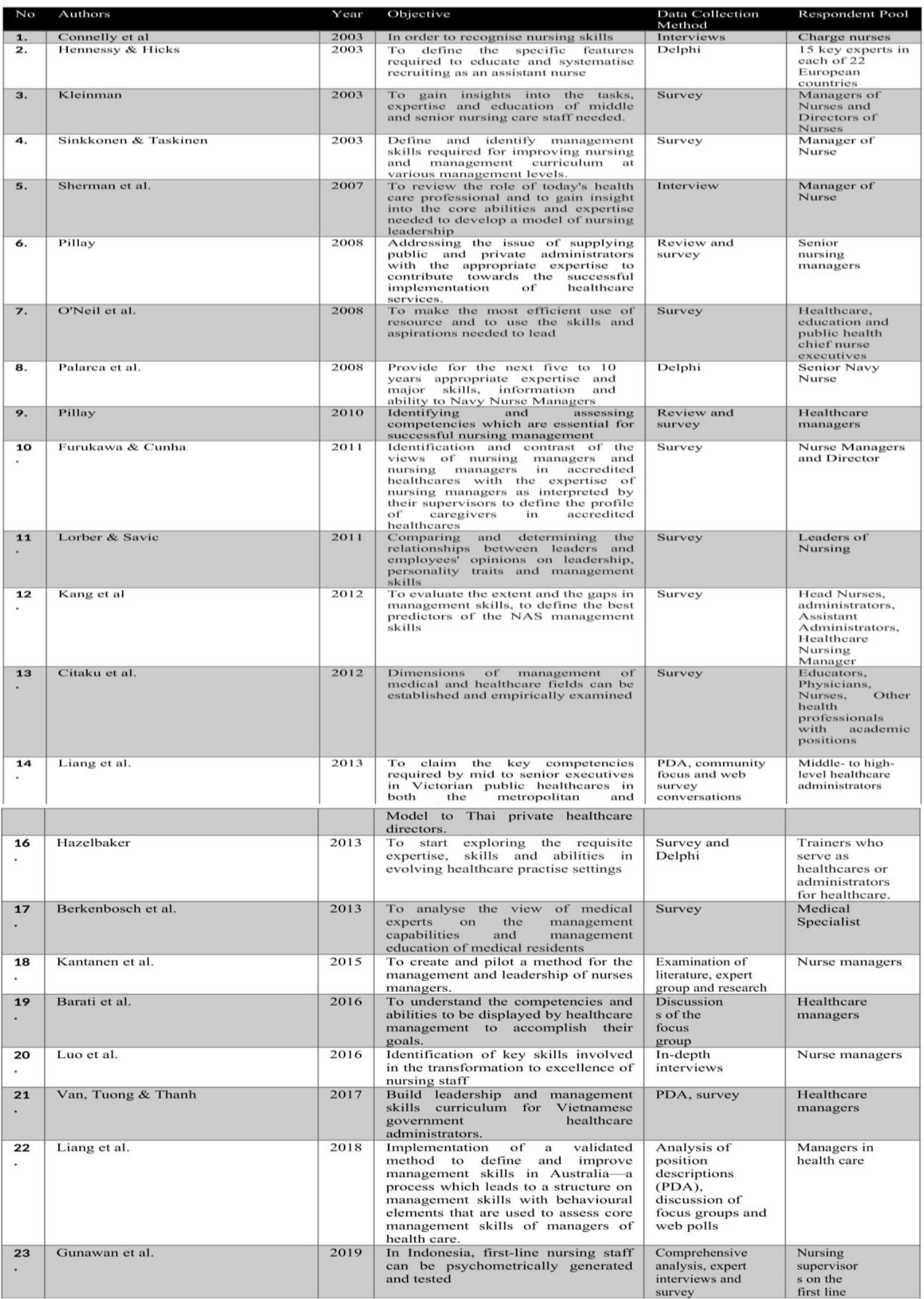

Table 1. List of literatures systematically reviewed

To analyze data on different resources of the administration and management competence, particularly in connection with the healthcare, the documents were subject to inductive content analyses. A number of words were used, including short sentences such as 
'financial data use'. These terms and clauses were grouped as interchangeable classes and were subsequently assessed in 23 separate subcategories.

\section{Results}

This research established seven key areas of leadership and management competencies: communication, transition or change, professionalism, evidence, healthcare skill, operational, and general healthcare. Each group was composed of similar subcategories.

\section{Communication}

Effective health information communicating can encourage patients and their family members to engage in their care as complete partners and have seen to increase commitment to medication and self-management. It requires relationship management and coordination and collaboration, and the consistency of the individual (Liang et al., 2018, Van Tuong \& Thanh, 2017; Barati et al., 2016; Luo et al., 2016; Wongprasit, 2015; Liang et al., 2013; Pillay, 2008; Sherman et al., 2007;

Connelly, Yoder \& Miner-Williams, 2003). It involves:

a. Relationship Management and Teamwork - Experts believe that collaboration and coordination skills are necessary for the provision of quality health care to increase the welfare of patients. Health care teams can optimize patient outcomes, reduce medical mistakes, maximize productivity, and maximize patient loyalty as both clinical and non-clinical personnel collaborate effectively (Schmutz, Meier \& Manser, 2019).

b. Communication - According to Anderson et al. (2019), the message has to be conveyed and packaged thoughtfully. Tone and body language will either muddy up the details or increase its accuracy. Structure of the text and style accuracy will have the same impact if it is printed. If these factors are not taken into consideration by healthcare providers, coordination begins to break down and the quality of treatment plummets.

c. Personal Quality - To abide by the rules and preserve a neat look, health care staff must take extra care. Good health is also important and requires a good diet, daily physical exercise, ample sleep, control of stress, good posture, and the prevention of harmful substances (Salyers et al., 2017).

\section{Transition or Change}

If they increase quality and protection or save money, improvements in healthcare practice are welcome. It is vital for medical care to be tailored to the needs of local communities. The rate of transformation in healthcare is accelerating, not slowing down. The dominant forces shaping healthcare will create tremendous economic opportunities for anyone who can use productive survival strategies in the near term and prepare for long-term prosperity at the same time. (Johnson et al., 2016) mention that a company must leverage the forces pushing transition and use them to its benefit.

There are three aspects involved in facilitating and manageing improvements within the provider of healthcare; the planning of changes to meet potential demands, including risk management; the efficiently manageable method of transition adoption and evolution; the transparency and personal responsibility of leading quality in exchange (Gunawan et al., 2019; 
Liang et al., 2018; Barati et al., 2016; Kantanen et al., 2015; Liang et al., 2013; Pillay, 2008; Sherman et al., 2007; Connelly, Yoder \& Miner-Williams, 2003).

Professionalism

Professionalism in healthcare is a belief framework about how best to coordinate and provide health care. It calls on community members to collectively declare ('profess') what the public and individual patients should anticipate concerning common expectations of competence and ethical principles (Luo et al., 2016; Kantanen et al., 2015; Wongprasit, 2014; Liang et al., 2013).

\section{Evidence}

Evidence-based treatment is widely implemented in the curriculum and wellness services for undergraduate, postgraduate, and continuing professional development. A structured collection of minimum core competencies in EBP that should be met by health practitioners could standardize and expand EBP education.(Albarqouni et al., 2019). Evidence-based practice is the "integration of scientific experience and patient principles with the best scientific evidence". Healthcare professionals make a medical decision for their patients based (Gunawan et al., 2019; Liang et al., 2018; Barati et al., 2016; Kantanen et al., 2015; Liang et al., 2013; Luo et al., 2016; Kantanen et al., 2015; Wongprasit, 2014; Liang et al., 2013; Pillay, 2010; Pillay, 2008; Sherman et al., 2007; Connelly, Yoder and Miner-Williams, 2003). It involves:

a. Evidence appraisal - After searching for facts, determination proces is needed if it is true and relevant before determining whether we should use it on our patients. The order in which value and significance are taken into consideration depends on individual choice. The assessment of proof is the systematic evaluation of scientific research papers to determine: are the conclusions of the analysis valid.

b. Evidence application and decision-making - The Network for Preventive and Chronic Treatment aims to extend the database available for evidence-based practice. It aims to ensure that physicians have the resources to bring expertise into practice. Sciencebased treatment is the use of the best available evidence along with the experience of a clinician and the beliefs of a patient.

c. Evaluation of decision - The willingness of a patient to understand the positives and consequences of a proposed diagnosis or intervention (including no treatment) and the alternatives is medical decision-making ability. Patients can make informed decisions if they can show comprehension of the condition, knowledge of the implications of their choice, and rationale in their cognitive process. At a patient experience, the potential is measured intuitively and is typically readily evident.

\section{Healthcare Skill}

The expertise in health care was categorized into four subcategories: social, educational, corporate, and economical. Social sophistication includes the recognition and appreciation of political and social governing systems' rules, obligations, and objectives (Berkenbosch et al., 2013a; O' Neil et al., 2008; Hennessy \& Hicks, 2003; Sinkkonen \& Taskinen, 2003) have also demonstrated that through their approach to health policy and health research, Finland has proved to be a huge challenge to the quality and cost-effectiveness of medical treatment. This subcategory covered managers' management practices and work content. The studies examined reflected knowledge about processes of organisations (Hazelbaker, 2013; Connelly 
et al., 2003; Kleinman, 2003; Sinkkonen \& Taskinen, 2003). The business expertise of this community was to include the knowledge, comprehension and implementation of business skills in clinical and cultural environments (Hazelbaker, 2013; Kang et al., 2012). Few studies (Berkenbosch et al., 2013a; O Neil et al., 2008) have shown an appreciation of the healthcare industry and the healthcare market in a greater context than financing including the manufacture of programs and facilities (Palarca et al., 2008; O' Neil et al., 2008; Sherman et al., 2007; Connelly et al., 2003; Kleinman, 2003; Sinckonen \& Taskinen, 2003). Financial skills have been shown to have an effect on the function of nursing managers (Liang et al., 2018; Van Tuong \& Thanh, 2017; Barati et al., 2016; Luo et al., 2016; Kantanen et al., 2015; Wongprasit, 2014; Liang et al., 2013; Liang et al., 2013; Pillay, 2010; Pillay, 2008; Sherman et al., 2007; Connelly, Yder \& Miner-Williams, 2003).

\section{Operational}

Organizational excellence, included: Procedures, operations, healthcare expertise, and growing skill. Expertise methodologies included areas such as product improved operating systems (Berkenbosch et al., 2013a; Lorber \& Savaq, 2011; Furukawa \& Cunha, 2011; O' Neil et al., 2008; Connelly et al., 2003). The desire to run wards with nursing experience (Berkenbosch et al., 2013a) was part of operational competence. This subcategory was distinguished by a thorough comprehension of procedures and available tools, management roles, and the delegated abilities (Furukawa \& Cunha, 2011; Lorber \& Savie, 2011). This subset also included leadership and corporate strategy skills such as capital management and management (Berkenbosch et al., 2013a; Hazelbakeer, 2013; Kang et al., 2012; Furukawa \& Cunha, 2011; Hennessy \& Hicks, 2003). This sub-group also included management expertise and management.

Awareness and expertise in both professional and clinical practises and professional ethics have been included within medical competence (Sherman et al., 2007; Connelly et al., 2003; Hennessy \& Hicks, 2003). Professional credibility, mistake, and error learning (Berkenbosch et al., 2013a; Sherman et al., 2007) have also been included. Management skills included workforce development and progression. This requires right of access and use (Citaku et al., 2012; Furukawa \& Cunha, 2011; Palarca et al., 2008; Connelly et al., 2003; Sinkkonen \& Taskinen, 2002). The unit also offered a realistic approach to clinical and operational processes improvements and consequences (Liang et al., 2018; Wongprasit et al., 2014; Barati et al., 2013; Liang et al., 2013; Pillay, 2008; O’ Neil et al., 2008; Palarca et al., 2008; Sherman et al., 2007; Connelly, Yoder \& Miner-Williams, 2003).

\section{General Healthcare}

Both from time control to collaboration, competitive mentality; thought and execution skills, and human resource management included the following sub-categories: health professionals became familiar with the third category, corporate management, and communication qualities. Time management was the capacity for preparing time and management skills (Hazelbaker, 2013; Kang et al., 2012; O’ Neil et al., 2008; Sinkkonen \& Taskinen, 2003). Interpersonal skills have been associated closely with management and management, including teamwork and interpersonal relationship building and preservation.

These are commonly described by both studies as management and leadership skills but there are various meanings, consisting of components such as team skills, decency, honesty, organizational skills, building loyalty, developing employees, and building working relationships within the company. Some papers documented leadership skills including 
communication and compliance with knowledge flow (Sinkkonen \& Taskinen, 2003; Hennessy \& Hicks, 2003; Lorsber et al., 2008; Palarca et al., 2008; Sherman et al., 2007).

The strategic mentality contained considerable expertise in strategic analysis, strategic process, direction, and implementation of strategies. The word 'strategic' has not been merged in a couple of publications (Hazelbaker, 2013; Berkensbosch et al., 2013a; Kang et al., 2012; Sinkkonen \& Taskinen, 2003; Connelly et al., 2003) with 'think', 'planning job management', 'visual', 'view', 'goals', 'vision', and 'mission'. The sub-category of strategic mentality further demonstrated the extent at which the boss worked, which ranged from empowering workers to fulfilling the mission and strategic planning. Critical thought, performance focus and skills to convey strategies, visions and work have been included in the strategic mindset sub-category (Citaku et al., 2012; Lorber \& Savic, 2011; Furukawa \& Cunha, 2011; Palarca et al., 2008; O' Neil et al., 2008; Sherman et al., 2007; Hennessy \& Hicks, 2003; Kleinman, 2003).

The willingness to think and apply involved an innovative mindset, concentration, multitasking, and use of decision-making and problem-solving experience. In the studies and the overall management and leadership category, the ability to gather and present a constructive contribution and mediation skills were also established. Publications are also found in selfconsciousness, strategic orientation, honesty and personal superiority (Hazelbaker, 2013; Kang et al., 2012; Citaku et al., 2012; O' Neil et al., 2008; Sherman et al., 2007; Hennessy \& Hicks, 2003; Sinkkonen \& Taskinen, 2003).

Management of human resource includes handling and producing human resources and mastering workers. The management of human resource (Liang et al., 2018; Van Tuong \& Thanh, 2017; Barati et al., 2016; Luo et al., 2016; Kantanen et al., 2015; Wongprasit, 2014; Liang et al., 2014; Liang et al., 2013; Kang et al., 2013) was among the main leadership and management skills in the area of nursing science.

\section{Discussion}

This research sought to describe healthcare management and managers' leadership and leadership skills in hospital environments. The method consisted of both evaluating the knowledge and science of many medical practitioners. Expertise, skills, personalities, and strengths that require management and leadership roles were included. We have also used inductive content analysis to obtain data from a systematic literature review collection of 23 publications. Our conclusions may be based on expertise clustered into seven major divisions: Communication, transition or change, professionalism, evidence, health care skill, operational and general healthcare. Whilst not so clearly, it was the most common trait, it was intelligence, but experience, ability and attitudes.

Only a few experiments were carried out to understand the skill criteria for the administration of healthcare. Only a limited number of health service management training programmes have adopted the idea of competence-based education and training. In nations who also have to develop their own management skills scheme to lead training and strengthen their health care staff, these inclusive skills can be checked and recruited (Liang et al., 2014).

The seven core competencies included have been explored and acknowledged. Behavioural aspects can not extend similarly to hospital management in Australia and Iran in either of the jurisdictions. In other situations, interpersonal aspects important to hospital managers are not equally significant, for example, for nursing managers if the principal roles they have to fill are different. No question their importance as key skills which health 
managers monitor to effectively execute their administrative functions must also be taken into account (Liang et al., 2018). While the framework lacks conduct elements essential to technical competence, the thoroughness of literature analysis and mapping has increased the need for professionalism. Professionalism stands out because of its capacity, including responsibility to patients (Stefl, 2008).

Healthcare institutions, especially hospitals, have implemented a patient-centered strategy today. Health employees should meet good ethical and moral expectations for patients and ensure up-to-date preparation and expertise in order for them to access high quality counselling. The aim is to ensure that the management results are correct and sustain their expectations (Kitreerawutiwong et al., 2015). Hence, discipline entails advancing the instruction and training of healthcare programs (Dorji et al., 2019).

A variety of forms to access management skill advancement can be found by managers. There are many tools to achieve this including formal instruction in university management (Briggs, 2008). Competency-based programs and training for health care management are recommended. The structure should be used in combination with a clear assessment process. The training needs of managers (Campion et al., 2011). Besides, this model can act as a benchmark for preparing and inspiring healthcare administrators.

In the short term, identifying and strengthening the management capability system will increase the value of current informal and organized training. The paradigm focuses on the longer-term skill needs of the overall health care management staff, including input on system growth and leadership strategies. Psychological, operational and financial dimensions cover the position of managers needing contextual know-how. Public services have allowed many European countries to adapt to market-like structures and management mechanisms. The typical course of action is also being put into question by the current integration targets and motions for the reorganisation of hospitals as procedural procedures (Piechota, 2016). In short, management and leadership growth and managerial positions in various countries with diverging health policy and budgets are addressed.

For managerial role, procedures, operative, clinical and developmental expertise have proved to be important. However, appointing new nursing administrators to leadership without proper training has also been a poor experience (Townsend \& Mowbray, 2020). The same needs training for most healthcare citizens in the Netherlands, Denmark, Canada and Australia in the growth of management abilities (Farver, Smalling \& Stoller, 2016). A research article (Crewe \& Girardi, 2020) has demonstrated that methods have been systematically followed to improve professional expertise and interpersonal skills.

Only a few years later, the condition remains unchanged (Kantanen, 2017) has shown. However both medical and nursing studies have encountered common obstacles. Management roles and obligations, for example, were different and experience, competence and attitude requirements were specified (Geerts, 2018). All studies were notable and popular in general, including management and management skills, including time management, communication skills, critical thinking, applied skills, and management of staff. The following categories also contain studies on particular forms of competencies for business, techniques, and general (Wiseman, 2017). Since the organization's roles and roles differ by degree, different administrators often need to apply their expertise. Managers need the skills of leadership to inspire and educate workers at all corporate levels. The management and leadership influence is enhanced through the management and organizational strategy-related growth initiatives (Larsson, Holmberg \& Kempster, 2020). The 
most recent research reviewed centred on job and human approaches to leadership, education, and growth (Siquiera et al., 2019).

In general hospitals and healthcare settings, the discrepancies between the occupations (Alvehus \& Andersson, 2018) became a strong cultural dimension. Also, during the initiation of the procedure orientation, the limits between medical specialties in Sweden were found. A direct outcome of boundaries is that improvements in professional structures have been tougher than adjustments of management processes (Brunetto et al., 2018). Doctors have no organisational and leadership skills support under the tradition of the medical profession (Lindsay, Kumar \& Juleff, 2020). In Norway, the hospital changes have continuously aimed to create stronger management roles as an indication that a convention of less technical authorities has shifted with a stronger emphasis on administrative function. Physicians have reduced as a temporary assignment or a job-trap after the Hospital Reformation in Norway, instead of administration's clinical practise, but management ambitions have declined (Berg et al., 2017).

Experience-oriented leadership and management strategy is straightforward. We analysed the study results that the study reported was structured to recognise management attributes, leadership features and different position in care entry (Admi \& Eilon-Moshe, 2016). Although the views of the sample differed, the aim was the same for everybody. In particular, the role in Finland of the manager and the need for training in management skills (Fanelli et al., 2020) are obvious. Study conducted by Sherman et al. (2007) to enhance management and leadership capabilities through education and training and the development of a management model. Through this study, organisational skills and management abilities and critical capabilities, experience and experience were also intended to predict similar characteristics. The academic field has already received skills evaluation and evaluations (Lucas et al., 2018), except the systemized finance, management, and leadership curricula and preparedness. The need for management education is recognised in health science management studies and in particular the need for management education in medicine.

Management and communication qualities are now widespread by formal schooling. However, managerial progress is abundantly accomplished by expertise and procedures, according to Farashahi and Tajeddin (2018). The successful management role requires a change of mind and attitudes towards skills and knowledge growth through informal modes. This is regularly done in an informal format by instructors, peers, and coaches and is an instrument to develop leadership capabilities and management strategies in an organization (Belasen \& Belasen, 2016). The willingness of physicians to perform administrative work (Geerts, Goodall \& Agius, 2020; Onyura et al., 2019) is affirmed by teamwork and leadership skill building, promoting, and preparation.

Developed frameworks have been published to resolve the criteria for jointly improving health managers and administrators' skills at different levels during their working practices in the USA and other countries (O'Connor, 2017) or study as a roadmap to clinical administration and leadership. For the future of health, it is important to establish systematically best-coordinated leaders and managers. In organisation's and strategic words, the most relevant issue, which occupation has not the role of management is management and its organised processes and versatility.

Various factors limit systematic approaches to healthcare and leadership development. Managers and leaders should be able not be portrayed as a priority or professional challenge in the conventional political management and management strategy at all stages, but should pursue management and leadership in health management research in an inclusive context. 
In the future, an internationally shared challenge for healthcare is a learning atmosphere where administrators and managers can work within the organisation with the requisite tools and opportunities to reflect and analyse their positions. The influence of the medical center leadership training programs, Saravo, Netzel and Kiesewetter (2017) have recently studied; they have established modest results and need for a thorough assessment of these programs. The most important issues include integrating business and management skill building methods and operational approaches with enhancing management efficiency in line with the objectives of the enterprise.

The study's structure and methodology have been narrowly applied, but most articles have identified different features of the requisite expertise between the health care practitioners and leaders, illustrating the fact that management and leadership analysis is more complex in nursing than in medicine. Management and leadership qualities in physician and politician fields are similar, although some reviews have supported these views and proposed that more research should be carried out.

\section{Discussion}

The paper outlines the results of a systematic literature study of competence studies in the field of health care management and analyses management capabilities mapping methods and outcomes using the defined framework. This recommendation requires an inclusive structure of management skills comprised of seven core leadership and management skills as illustrated in Figure 2.

Figure 2. Seven key areas of leadership and management competencies

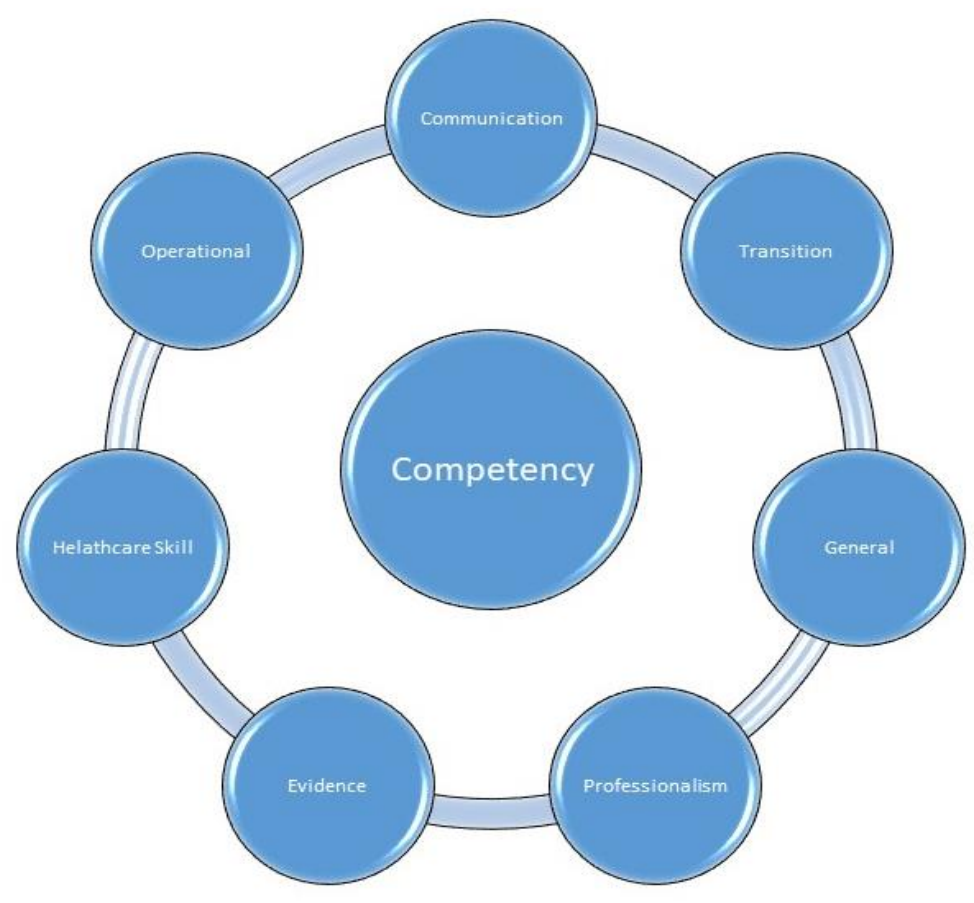


While the predicted structure does not explicitly differentiate the distinction between fields, management levels, and positions in the level of expertise required, it offers a very valuable reference for the revision and improvement of the existing curriculum for preparation and development of healthcare management and for the identification and recruiting of applicants for different management roles in the healthcare environment.

For the individual approach, as previously indicated, to leadership and management abilities and organisational and strategic types, an organised, unified management approach lacking in the study will be essential. The majority of studies reviewed have identified different aspects of the requisite skills in nurses' management and leaders. The management and leadership skills needed by physician managers are, however, similar, but studies have not been established which combine the points of view of the nursing and physician management. The development of a learning atmosphere where supervisors and managers work at the organisation with a great deal of assistance and an ability to analyse and review their job is therefore a global challenge for future healthcare. The system must combine traditional non-professional management skills and leadership skills to promote shared understanding of management and leadership in the organisation.

In brief, management and leadership growth strengthens creatively and consistently the overall corporate efficiency and core management roles and leads to young, empowered, and ultimately leading managers. The leadership and management credentials required for the future include an interesting path and a task to be evaluated further using creative evaluation methods. More knowledge and a variety of viewpoints on the appropriate characteristics and expertise management approaches to be established in the future may be offered by international organizations of health care specialists who serve as subjects for research.

\section{Acknowledgements}

The authors are grateful to the Faculty of Education, UKM for assistance in improving the manuscript via professional services with the utilization of research funding (Code: GG-2017019).

\section{References}

Admi, H., Eilon-Moshe, Y. (2016). Do hospital shift charge nurses from different cultures experience similar stress? An international cross sectional study. International Journal of Nursing Studies, 63, 48-57.

Alvehus, J., \& Andersson, A. (2018). A new professional landscape: Entangled institutional logics in two Swedish welfare professions. Nordic Journal of Working Life Studies, 8(3), 91-109.

Albarqouni, L., Hoffmann, T., \& Glasziou, P. (2018). Core competencies in evidence-based practice for health professionals: Consensus Statement Based on a Systematic Review and Delphi Survey." JAMA Network Open, 1(2).

Anderson, R. J., Bloch, S., Armstrong, M., Stone, P. C., \& Low, J. T. S. (2019). Communication between healthcare professionals and relatives of patients approaching the end-of-life: A systematic review of qualitative evidence. Palliative Medicine, 33(8), 2019, 926-41.

Barati, O., Sadeghi, A., Khammarnia, M., E. Siavashi, E., \& Oskrochi, G. (2016). A qualitative study to identify skills and competency required for hospital managers. Electronic Physician, 8(6), 2458-65.

Barr, J., \& Dowding, L. (2019). Leadership in health care. SAGE Publications Limited. 
Belasen, A, \& Belasen, A. R. (2016). Value in the middle: Cultivating middle managers in healthcare organizations. Journal of Management Development, 35(9), 1149-1162.

Berg, L. N., Puusa, A., Pulkkinen, K., \& Geschwind, L. (2017). Managers' identities: Solid or affected by institutional logics and organizational ammendments?, 21(1), .

Berkenbosch, L., Bax, M., Scherpbier, A., Heyligers, I., Muijtjens, A. M. M., \& Busari, J. O. (2013). How Dutch medical specialists perceive the competencies and training needs of medical residents in healthcare management. Medical Teacher, 35(4).

Bowers, S. (2019). Nurse Perspective on Nurse Manager Leadership Phenomenological Study.

Briggs, D. S. (2008). SHAPE declaration on the organisation and management of health services: A call for informed public debate. Asia Pacific Journal of Health Management, $3(2), 10$.

Brunetto, Y., Xerri, M., Trinchero, E., Beattie, R., Shacklock, K., Farr-Wharton, R., \& Borgonovi, E. (2018). Comparing the impact of management on public and private sector nurses in the UK, Italy, and Australia. Public Management Review, 20(4), 525-44.

Campion, M. A., Fink, A. A., Ruggeberg, B. J., Carr, L., Phillips, G. M., \& Odman, R. B. (2011). Doing competencies well: Best practices in competency modeling. Personnel Psychology, 64(1), 225-262.

Çitaku, F., Violato, C., Beran, T., Donnon, T., Hecker, K., \& Cawthorpe, D. (2012). Leadership competencies for medical education and healthcare professions: population-based study. BMJ Open, 2(2).

Crewe, S., \& Girardi, A. (2020). Nurse managers: Being deviant to make a difference. Journal of Management and Organization, 26(3), 324-339.

de Oliveira, P., \& Cunha, I. C. K. O. (2011). Profile and competencies of nurse managers at accredited hospitals. Revista Latino-Americana de Enfermagem, 19(1), 106-114.

Erebouni, A., Wålinder, R., Andersen, A. R., \& Rudolfsson, G. (2020). Nurse managers in perioperative settings and their reasons for remaining in their jobs: A qualitative study. Journal of Nursing Management, 28(6), 1191-1198.

Fanelli, S., Lanza, G., Enna, C., \& Zangrandi, A. (2020). Managerial competences in public organisations: The healthcare professionals' perspective. BMC Health Services Research, 20(1), 1-9.

Farashahi, M., \& Tajeddin, M. (2018). Effectiveness of teaching methods in Business Education: A comparison study on the learning outcomes of lectures, case studies and simulations. International Journal of Management Education, 16(1), 131-142.

Farver, C. F., Smalling, S., \& Stoller, J. K. (2016). Developing leadership competencies among medical trainees: Five-year experience at the Cleveland Clinic with a chief residents' training course." Australasian Psychiatry, 24(5), 499-505.

Geerts, J. M., Goodall, A. H., \& Agius, S. (2020). Evidence-based leadership development for physicians: A systematic literature review. Social Science and Medicine, 246, p. 112709,

Gunawan, J., Aungsuroch, Y., Fisher, M. L., \& McDaniel, A. M. (2019). Development and psychometric properties of Managerial Competence Scale for first-line nurse managers in Indonesia. SAGE Open Nursing, 5, 1-12.

Hazelbaker, C. B. (2013). Perceived skills and abilities required by athletic trainers in hospital and clinical management positions: A Delphi study. Journal of Athletic Training, 48(1), 2013, 87-91.

Hennessy, D., \& Hicks, C. (2003). The ideal attributes of chief nurses in Europe: A Delphi study. Journal of Advanced Nursing, 43(5), 441-48. 
Kang, C. M., Chiu, H. T., Hu, Y. C., Chen, H. L., Lee, P. H., \& Chang, W. Y. (2012). Comparisons of self-ratings on managerial competencies, research capability, time management, executive power, workload and work stress among nurse administrators. Journal of Nursing Management, 20(7), 938-947.

Kantanen, K., Kaunonen, M., Helminen, M., \& Suominen, T. (2015). The development and pilot of an instrument for measuring nurse managers' leadership and management competencies. Journal of Research in Nursing, 20(8), 667-77.

Kitreerawutiwong, K., Sriruecha, C., \& Laohasiriwong, W. (2015). Development of the competency scale for primary care managers in Thailand: Scale development. BMC Family Practice, 16(1), 174.

Kleinman, C. S. (2003). Leadership roles, competencies, and education: How prepared are our nurse managers? JONA: The Journal of Nursing Administration, 33(9), 451-455.

Larsson, M., Holmberg, R., \& Kempster, S. (2020). It's the organization that is wrong: Exploring disengagement from organizations through leadership development. Leadership, 16(2), 141-162.

Liang, Z., Blackstock, F. C., Howard, P. F., Briggs, D. S., Leggat, S. G., Wollersheim, D., Edvardsson, D., \& Rahman, A. (2018). An evidence-based approach to understanding the competency development needs of the health service management workforce in Australia." BMC Health Services Research, 18(1), 1-12.

Liang, Z., Howard, P. F., Koh, L. C., \& Leggat, S. G. (2013). Competency requirements for middle and senior managers in community health services. Australian Journal of Primary Health, 19(3), 256-263.

Liang, Z., Leggat, S. G., Howard, P. F., \& Koh, L. C. (2013). What makes a hospital manager competent at the middle and senior levels. Australian Health Review, 37(5), 566-573.

Lindsay, C. F., Kumar, M., \& Juleff, L. (2020). Operationalising lean in healthcare: The impact of professionalism. Production Planning and Control, 31(8), 629-43.

Lockeman, Kelly S., et al. (2019). Validity evidence and use of the IPEC Competency SelfAssessment, version 3. Journal of Interprofessional Care, vol. 00, no. 00, pp. 1-7.

Lorber, M., \& Savič, B. S. (2011). Perceptions of managerial competencies, style, and characteristics among professionals in nursing. Croatian Medical Journal, 52(2), 198204.

Lucas, R., Goldman, E. F., Scott, A. R., \& Dandar, V. (2018). Leadership development programs at academic health centers: Results of a national survey. Academic Medicine, 93(2), 229-36.

Mansouri, R., Neishabouri, M., \& Gorji, M. A. H. (2019). Exploring the human factors affecting health service managers: A qualitative study. Open Access Macedonian Journal of Medical Sciences, 7(12), 2017-2023.

O'Connor, M. (2017). On-boarding the middle manager. Nursing Administration Quarterly, 41(4), 360-367.

O'Neil, E., Morjikian, R. L., Cherner, D., Hirschkorn, C., \& West, T. (2008). Developing nursing leaders: an overview of trends and programs. JONA: The Journal of Nursing Administration, 38(4), 178-183.

Onyura, B., Crann, S., Freeman, R., Whittaker, M, \& Tannenbaum, D. (2019). The state-of-play in physician health systems leadership research: A review of paradoxes in evidence. Leadership in Health Services, 32(4), 620-643. 
Piechota, A. M. (2016). Level and conditions of social acceptance of co-payments for general practitioner and medical specialist advice. Acta Universitatis Lodziensis. Folia Oeconomica, 1(318), 79.

Pillay, Rubin. (2010). The skills gap in nursing management in South Africa: A sectoral analysis: A research paper. Journal of Nursing Management, 18(2), 134-144.

Pillay, R. (2008). Defining competencies for hospital management: A comparative analysis of the public and private sectors. Leadership in Health Services, 21(2), 99-110

Salyers, M. P., Bonfils, K. A., Luther, L., Firmin, R. L., White, D. A., Adams, E. L., \& Rollins, A. L. (2017). The relationship between professional burnout and quality and safety in healthcare: A meta-analysis. Journal of General Internal Medicine, 32(4), 475-82.

Saravo, B., Netzel, J., \& Kiesewetter, J. (2017). The need for strong clinical leaders: Transformational and transactional leadership as a framework for resident leadership training. PLoS ONE, 12(8), 1-13.

Schmutz, J. B., Meier, L. L., \& Manser, T. (2019). How effective is teamwork really? The relationship between teamwork and performance in healthcare teams: A systematic review and meta-analysis. BMJ Open, 9(9), 1-16.

Sherman, R. O., Bishop, M., Eggenberger, T., \& Karden. R. (2007). Development of a leadership competency model. Journal of Nursing Administration, 37(2), 85-94.

Sinkkonen, S., \& Taskinen, H. (2003). Nursing management skills. Superintendent's Magazine, 31(8), 4-19.

Siqueira, C. L., Bernadeli, A. C. F., Gasparino, R. C., Feldman, L. B., Cunha, I. C. K. O., \& Oliveira, R. A. (2019). Knowledge of responsible technical nurses on management skills: $A$ qualitative study. Revista Brasileira de Enfermagem, 72(1), 43-48.

Stefl, M. E. (2008). Common competencies for all healthcare managers: The healthcare leadership alliance model. Journal of Healthcare Management, 53(6), 360-373.

Van Tuong, P., \& Duc, N. T. (2017). A leadership and managerial competency framework for public hospital managers in Vietnam. AIMS Public Health, 4(4), 418-29.

Wongprasit, N. (2013). The leadership competencies model of private hospital directors in Thailand." HRD Journal, 4.1, 72-85. 